\title{
Synthesis and Microwave Absorption Properties of Core-Shell Structured $\mathrm{Co}_{3} \mathrm{O}_{4}$-PANI Nanocomposites
}

\author{
Hongyan Xu, ${ }^{1}$ Zhenyin Hai, ${ }^{2}$ Jiangtao Diwu, ${ }^{1}$ Qiang Zhang, ${ }^{2}$ Libo Gao, ${ }^{2}$ Danfeng Cui, \\ Junbin Zang, ${ }^{3}$ Jun Liu, ${ }^{2}$ and Chenyang $X_{u e}{ }^{2}$ \\ ${ }^{1}$ School of Materials Science and Engineering, North University of China, Taiyuan, Shanxi 030051, China \\ ${ }^{2}$ Key Laboratory of Instrumentation and Dynamic Measurement of Ministry of Education, North University of China, Taiyuan, \\ Shanxi 030051, China \\ ${ }^{3}$ North University of China, Shuozhou, Shanxi 036000, China
}

Correspondence should be addressed to Chenyang Xue; xuechenyang@foxmail.com

Received 16 May 2015; Accepted 16 August 2015

Academic Editor: Themis Matsoukas

Copyright (C) 2015 Hongyan Xu et al. This is an open access article distributed under the Creative Commons Attribution License, which permits unrestricted use, distribution, and reproduction in any medium, provided the original work is properly cited.

\begin{abstract}
The core-shell structured $\mathrm{Co}_{3} \mathrm{O}_{4}$-PANI nanocomposites have been successfully prepared using an in situ polymerization method, while the core $\mathrm{Co}_{3} \mathrm{O}_{4}$ nanoparticles were synthesized by carbon-assisted method using degreasing cotton as a template. The obtained samples were characterized by XRD, TEM, FTIR, and XPS. The results indicated that the amorphous PANI was well covered on the surface of the spinel $\mathrm{Co}_{3} \mathrm{O}_{4}$ and the $\mathrm{Co}_{3} \mathrm{O}_{4}$-PANI with core-shell structure was formed with particle size of about $100 \mathrm{~nm}$. The interfacial interaction of the core-shell nanocomposite greatly enhances the microwave absorption properties. The maximum reflection loss of $\mathrm{Co}_{3} \mathrm{O}_{4}$-PANI is up to $-45.8 \mathrm{~dB}$ at $11.7 \mathrm{GHz}$ with a thickness of $2.5 \mathrm{~mm}$ and the adsorption bandwidth with the reflection loss below $-10 \mathrm{~dB}$ reaches $14.1 \mathrm{GHz}$ ranging from 3.9 to $18 \mathrm{GHz}$ when the thickness is between 2 and $5.5 \mathrm{~mm}$. Therefore, the facilely synthesized and low-cost $\mathrm{Co}_{3} \mathrm{O}_{4}$-PANI nanocomposite with superior microwave absorption properties can be a promising nanomaterial for high efficient microwave absorption.
\end{abstract}

\section{Introduction}

With the wide use of electronic devices, the electromagnetic pollution has been a growing threat to the stable running of electronically controlled systems and more importantly to our healthy life $[1,2]$. Considerable attention has been attracted to the study on the high efficient and inexpensive microwave absorbing materials $[3,4]$. Of all the discovered microwave absorbing materials, due to its electric conductivity, lightweight, flexibility, stability, and ease of synthesis, polyaniline (PANI), as a traditional practical polymer, has been extensively employed in the synthesis of promising microwave absorbers, for instance, PANI-NiZn, PANI-CoFe $\mathrm{O}_{4}$, PANI- $\mathrm{Fe}_{3} \mathrm{O}_{4}$-graphene, and PANI- $\mathrm{Fe}_{3} \mathrm{O}_{4}$ MWCNTs [5-8].

$\mathrm{Co}_{3} \mathrm{O}_{4}$ is a normal spinel structured crystal with $\mathrm{Co}^{3+}$ occupying octahedral sites and $\mathrm{Co}^{2+}$ in tetrahedral sites within the lattice [9]. $\mathrm{Co}_{3} \mathrm{O}_{4}$ can act as a functional material in various fields, such as catalysts, lithium ion batteries, supercapacitor, and chemical sensors [10-15]. Recent studies have demonstrated that $\mathrm{Co}_{3} \mathrm{O}_{4}$ can also be used as excellent microwave absorption material. The porous Co$\mathrm{Co}_{3} \mathrm{O}_{4}$ hybrid hollow spheres synthesized by Wu et al. can absorb microwave with maximum reflection loss of $-18.5 \mathrm{~dB}$ at $6.5 \mathrm{GHz}$ when the thickness is $5.00 \mathrm{~mm}$ [16]. The $2 \mathrm{D}$ $\mathrm{Co}_{3} \mathrm{O}_{4} @ \mathrm{C} @ P G C$ fabricated by Wen et al. shows better microwave absorption properties [2]. The maximum reflection loss is $-32.3 \mathrm{~dB}$ at $11.4 \mathrm{GHz}$ with thickness of $2.3 \mathrm{~mm}$. The $\mathrm{CoO}_{x} / \mathrm{CFs}$ composite investigated by Liu et al. exhibits excellent microwave absorption performances [17]. The lowest reflectivity is $-45.16 \mathrm{~dB}$ at $13.41 \mathrm{GHz}$ with $1.5 \mathrm{~mm}$ in thickness. The RGO- $\mathrm{Co}_{3} \mathrm{O}_{4}$, PANI-RGO- $\mathrm{Co}_{3} \mathrm{O}_{4}$, and PPy-RGO- $\mathrm{Co}_{3} \mathrm{O}_{4}$ nanocomposites researched by Liu et al. have maximum reflection losses of $-43.7 \mathrm{~dB}$ at $13.8 \mathrm{GHz}$ (with a thickness 
of $3.3 \mathrm{~mm}$ ), $-32.6 \mathrm{~dB}$ at $6.3 \mathrm{GHz}$ (with a thickness of $3 \mathrm{~mm}$ ), and $-33.5 \mathrm{~dB}$ at $15.8 \mathrm{GHz}$ (with a thickness of $2.5 \mathrm{~mm}$ ), respectively [18-20].

In this work, we report a core-shell structured $\mathrm{Co}_{3} \mathrm{O}_{4}{ }^{-}$ PANI nanocomposite with a maximum reflection loss of up to $-45.8 \mathrm{~dB}$ at $11.7 \mathrm{GHz}$ when its thickness is $2.5 \mathrm{~mm}$. The coreshell $\mathrm{Co}_{3} \mathrm{O}_{4}$-PANI was synthesized by a facile, inexpensive, and scalable method and characterized by XRD, TEM, FTIR, and XPS. The behaviors of microwave absorption of $\mathrm{Co}_{3} \mathrm{O}_{4}$-PANI were investigated and the microwave absorbing mechanisms were also discussed.

\section{Experimental}

2.1. Preparation of $\mathrm{Co}_{3} \mathrm{O}_{4}$-PANI Nanocomposites. The spinel $\mathrm{Co}_{3} \mathrm{O}_{4}$ was synthesized by carbon-assisted method using degreasing cotton as a template. $17.46 \mathrm{~g} \mathrm{Co}\left(\mathrm{NO}_{3}\right)_{2} \cdot 6 \mathrm{H}_{2} \mathrm{O}$ was dissolved in $20 \mathrm{~mL}$ deionized water with magnetic stirring for $10 \mathrm{~min}$. Then $1.5 \mathrm{~g}$ degreasing cotton was immersed in the blood red solution and ultrasonicated for $10 \mathrm{~min}$ to disperse the ions on the degreasing cotton homogeneously. Then the treated degreasing cotton was transferred into a quartz Petri dish in the tube furnace (OTF-1200X-III, Heifei, China) and calcined at $600^{\circ} \mathrm{C}$ for $2 \mathrm{~h}$ in air to obtain $\mathrm{Co}_{3} \mathrm{O}_{4}$ nanoparticles.

The core-shell $\mathrm{Co}_{3} \mathrm{O}_{4}$-PANI nanocomposite was prepared by an in situ polymerization method. $0.9 \mathrm{~g}$ preprepared $\mathrm{Co}_{3} \mathrm{O}_{4}$ was added into $5 \mathrm{~mL}$ of $2 \mathrm{~mol} / \mathrm{L} \mathrm{HCl}$ diluted by $50 \mathrm{~mL}$ deionized water and kept for $1 \mathrm{~h}$ in an ultrasonic bath. Then $1.6 \mathrm{~mL}$ aniline was mixed in the solution and stirred vigorously for $30 \mathrm{~min}$. The aqueous solution of $\left(\mathrm{NH}_{4}\right)_{2} \mathrm{~S}_{2} \mathrm{O}_{8}$ (APS, $4.56 \mathrm{~g}$ was dissolved in $50 \mathrm{~mL}$ deionized water) was slowly added to the above mixture and stirred for $10 \mathrm{~h}$. The obtained precipitate was filtered and washed with $\mathrm{HCl}$, methanol, and deionized water in sequence repeatedly until the precipitate is neutral. Finally, the precipitate was dried at $60^{\circ} \mathrm{C}$ for $24 \mathrm{~h}$ and the $\mathrm{Co}_{3} \mathrm{O}_{4}$-PANI nanocomposite was obtained.

2.2. Characterization. The X-ray powder diffraction (XRD) was carried out using a Bruker D8 with $\mathrm{Cu} \mathrm{K} \alpha(\lambda=1.5406 \AA)$ radiation at $40 \mathrm{eV}$ in the $2 \theta$ of $20-80^{\circ}$. The morphology was observed by transmission electron microscopy (TEM, JEOL JEM-2011). Fourier transform infrared spectroscopy (FTIR) was recorded from $\mathrm{KBr}$ pellets in the range of $500-4000 \mathrm{~cm}^{-1}$ on an Avatar 360 spectrometer. X-ray photoelectron spectroscopy (XPS) was measured on an ESCALAB 250Xi spectrometer with a standard $\mathrm{Al} \mathrm{K} \alpha$ radiation with the binding energies calibrated based on the contaminant carbon $(\mathrm{Cls}=284.6 \mathrm{eV})$.

In order to measure the electromagnetic parameters, the samples were prepared by uniformly mixing the prepared nanomaterials with a paraffin matrix in the mass ratio of $1: 1$ and then pressing the mixture into a toroidal shaped compact $\left(\Phi_{\text {outer }}=7.00 \mathrm{~mm}\right.$ and $\left.\Phi_{\text {inner }}=3.04 \mathrm{~mm}\right)$. The electromagnetic parameters of the as-obtained samples were measured in the frequency range of $2.0-18.0 \mathrm{GHz}$ by an Agilent HP$8722 \mathrm{ES}$ vector network analyzer.

\section{Results and Discussions}

The XRD patterns of $\mathrm{Co}_{3} \mathrm{O}_{4}$ and $\mathrm{Co}_{3} \mathrm{O}_{4}$-PANI are shown in Figure 1. In the pattern of $\mathrm{Co}_{3} \mathrm{O}_{4}$, it can be observed that the diffraction peaks of $\mathrm{Co}_{3} \mathrm{O}_{4}$ at $2 \theta=31.3,36.9,38.5,44.8$,

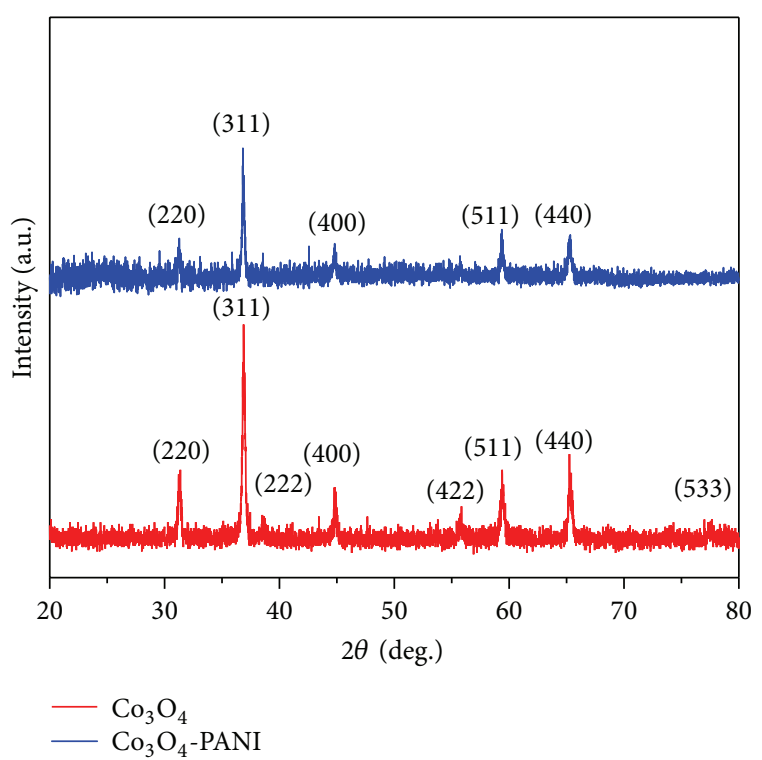

Figure 1: XRD patterns of $\mathrm{Co}_{3} \mathrm{O}_{4}$ and $\mathrm{Co}_{3} \mathrm{O}_{4}$-PANI.

$55.6,59.3,65.2$, and 77.3 can be assigned to the (220), (311), (222), (400), (422), (511), (440), and (533) planes of $\mathrm{Co}_{3} \mathrm{O}_{4}$, respectively, which is in accordance with JCPDS card of the standard spinel cubic $\mathrm{Co}_{3} \mathrm{O}_{4}$ (JCPDS number 42-1467) [21]. The crystallite size with respect to (311) peak of $\mathrm{Co}_{3} \mathrm{O}_{4}$ has been calculated by the Scherrer relation and is estimated to be $56.6 \mathrm{~nm}$. In the pattern of $\mathrm{Co}_{3} \mathrm{O}_{4}$-PANI, comparing to pure $\mathrm{Co}_{3} \mathrm{O}_{4}$, all peaks of $\mathrm{Co}_{3} \mathrm{O}_{4}$ become weaker and the peaks at $2 \theta=38.5,55.6$, and 77.3 are even too weak to be observed, which is on account of the PANI coating. There is a small hump when $2 \theta$ is below 30 . This is due to the periodicity parallel and perpendicular to the polymer chains which indicates the polyaniline is amorphous [22, 23]. The absence of the peaks of PANI in $\mathrm{Co}_{3} \mathrm{O}_{4}$-PANI nanocomposites is due to the presence of $\mathrm{Co}_{3} \mathrm{O}_{4}$ which has a great effect on forming PANI during the coating process. The interaction of PANI and $\mathrm{Co}_{3} \mathrm{O}_{4}$ in the interface blocks the crystallization of PANI [24]. Both the weakness of $\mathrm{Co}_{3} \mathrm{O}_{4}$ peaks and the lack of the PANI peaks in $\mathrm{Co}_{3} \mathrm{O}_{4}$-PANI prove that $\mathrm{Co}_{3} \mathrm{O}_{4}$ nanoparticles are well coated by PANI.

To investigate the morphology and structure of the products, TEM images were taken for $\mathrm{Co}_{3} \mathrm{O}_{4}$ and $\mathrm{Co}_{3} \mathrm{O}_{4}$ PANI and the corresponding results are presented in Figure 2. Figure 2(a) shows that the $\mathrm{Co}_{3} \mathrm{O}_{4}$ nanoparticles with a relatively small size are obtained. The edges are clear and round. It indicates that the particles are approximately spherical or ellipsoidal. The average size of nanoparticles is about $60 \mathrm{~nm}$, which is consistent with the calculation from XRD mentioned above. From Figure 2(b), we can see that a lot of wrinkled forms cover on the $\mathrm{Co}_{3} \mathrm{O}_{4}$ dark cores. The edges of particles are quite blur and amorphous, which is attributed to PANI. The formation of amorphous PANI supports the explanation about the lack of PANI peaks in $\mathrm{Co}_{3} \mathrm{O}_{4}$-PANI discussed before. After coating with PANI, the particle sizes of the coreshell nanocomposites are around $100 \mathrm{~nm}$. It can be observed in Figures 2(c) and 2(d) that the measured lattice spacing 


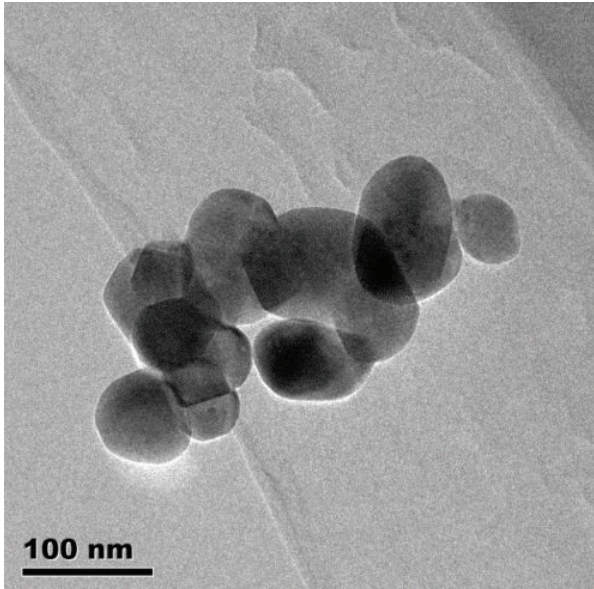

(a)

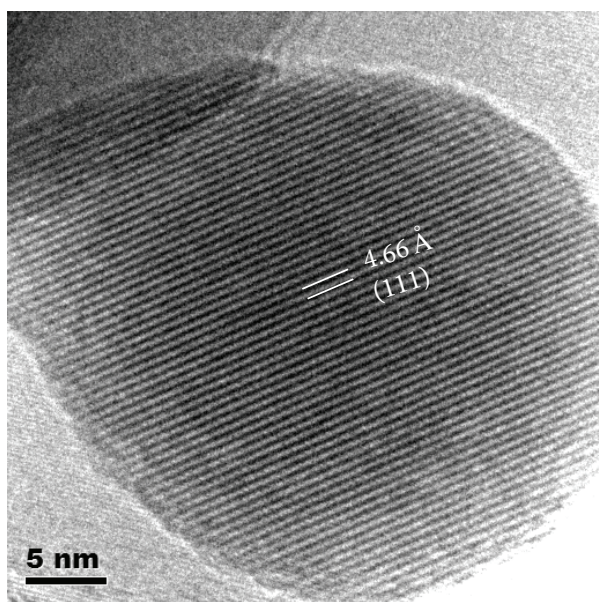

(c)

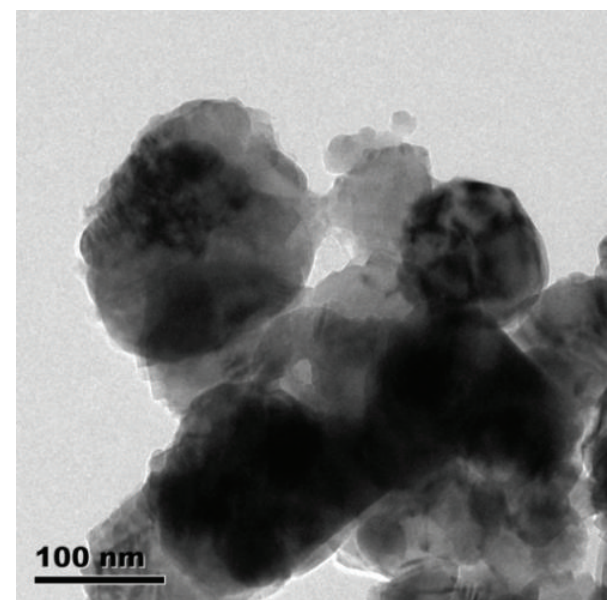

(b)

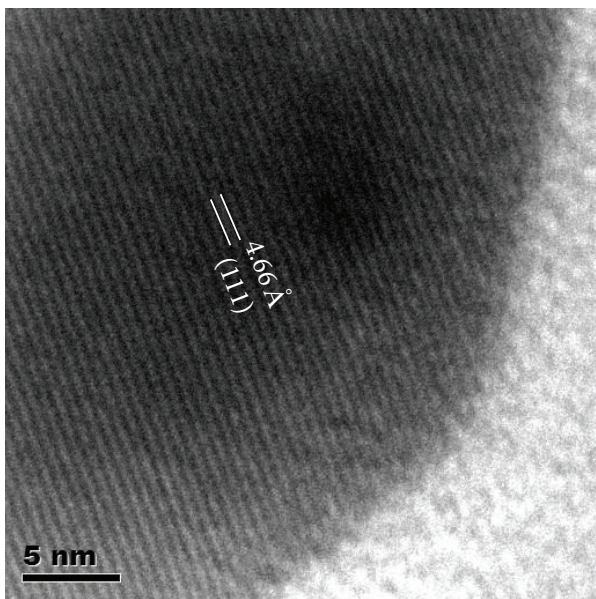

(d)

Figure 2: TEM images of $\mathrm{Co}_{3} \mathrm{O}_{4}$ (a) and $\mathrm{Co}_{3} \mathrm{O}_{4}$-PANI (b). HRTEM images of $\mathrm{Co}_{3} \mathrm{O}_{4}$ (c) and $\mathrm{Co}_{3} \mathrm{O}_{4}$-PANI (d).

is $4.66 \AA$ which is in line with the (111) interplanar distance of the $\mathrm{Co}_{3} \mathrm{O}_{4}$ [12]. The HRTEM analysis shows clear and continuous lattice fringes which further confirm the good crystal structure of prepared $\mathrm{Co}_{3} \mathrm{O}_{4}$.

The FTIR spectra of $\mathrm{Co}_{3} \mathrm{O}_{4}$ and $\mathrm{Co}_{3} \mathrm{O}_{4}$-PANI are shown in Figure 3. The sharp peaks at 572 and $661 \mathrm{~cm}^{-1}$ in the spectrum of $\mathrm{Co}_{3} \mathrm{O}_{4}$ are associated with the $\mathrm{OB}_{3}$ (B represents $\mathrm{Co}^{3+}$ in an octahedral hole) and the $\mathrm{ABO}$ (A represents the $\mathrm{Co}^{2+}$ in a tetrahedral hole) vibrations in the spinel lattice, respectively $[25,26]$. Both $\mathrm{Co}_{3} \mathrm{O}_{4}$ and $\mathrm{Co}_{3} \mathrm{O}_{4}$-PANI have two peaks at 1118 and $1398 \mathrm{~cm}^{-1}$. The peak at $1118 \mathrm{~cm}^{-1}$ is attributed to the stretching vibrations of $\mathrm{C}-\mathrm{O}$ and $\mathrm{CO}_{3}{ }^{2-}$ anions. They are introduced by the burn of degreasing cotton during the preparation procedure of $\mathrm{Co}_{3} \mathrm{O}_{4}$. The peak at $1398 \mathrm{~cm}^{-1}$ is corresponding to the stretching vibration of $\mathrm{NO}_{3}{ }^{-}$, which is due to the residue of $\mathrm{Co}\left(\mathrm{NO}_{3}\right)_{3}$ [12]. The peaks at 1642 and $3465 \mathrm{~cm}^{-1}$ in the spectrum of $\mathrm{Co}_{3} \mathrm{O}_{4}$ are assigned to molecular water and $\mathrm{O}-\mathrm{H}$ [27]. In the spectrum of $\mathrm{Co}_{3} \mathrm{O}_{4}-$ PANI, other than the influence of molecular water and O$\mathrm{H}$, the bands at 1644 and $3446 \mathrm{~cm}^{-1}$ are also affected by the quinoid ring and $\mathrm{N}-\mathrm{H}$ stretching of PANI, separately $[24,28,29]$. In the spectrum of $\mathrm{Co}_{3} \mathrm{O}_{4}$-PANI, the very small

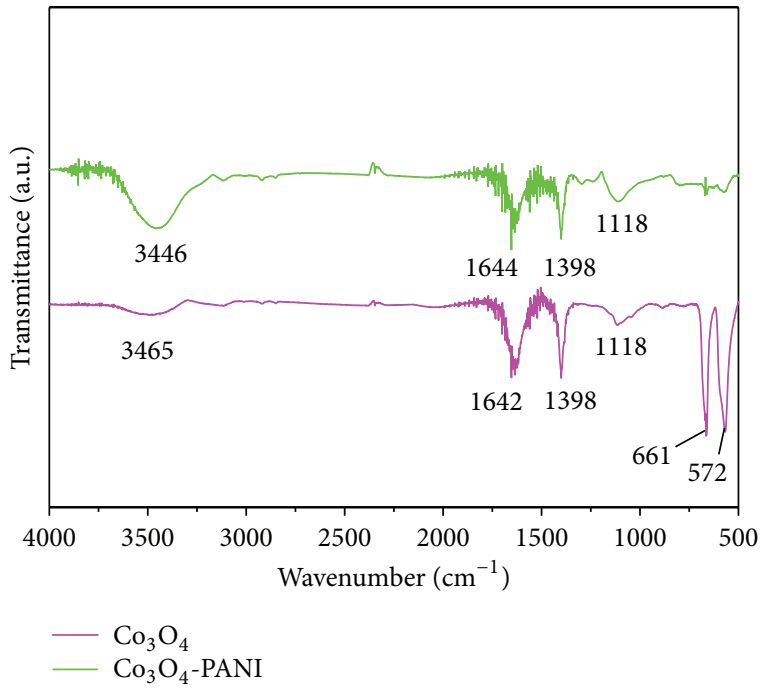

FIGURE 3: FT-IR spectra of $\mathrm{Co}_{3} \mathrm{O}_{4}$ and $\mathrm{Co}_{3} \mathrm{O}_{4}$-PANI.

peaks between 1118 and $1644 \mathrm{~cm}^{-1}$ are due to the existence of PANI. The absence of the characteristic peaks of $\mathrm{Co}_{3} \mathrm{O}_{4}$ 


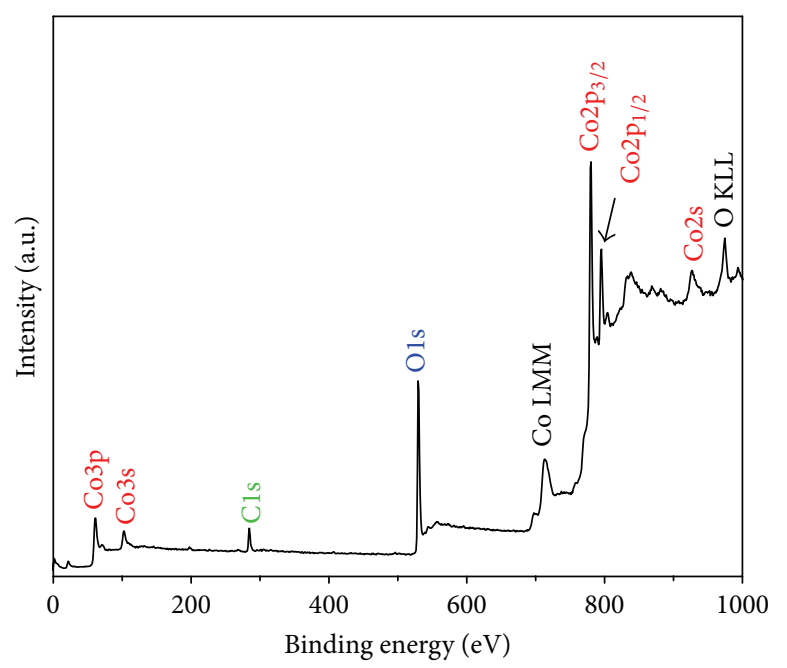

(a)

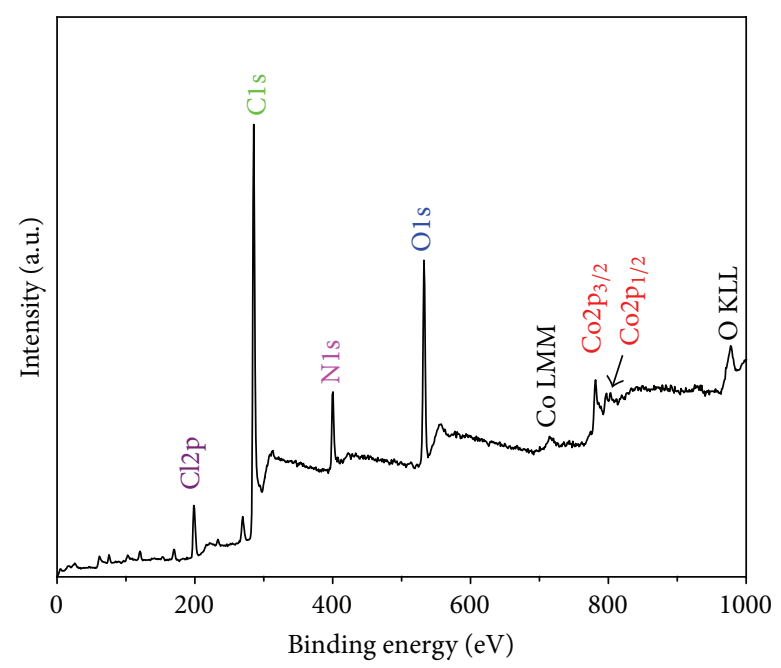

(b)

FIgURE 4: XPS spectra of $\mathrm{Co}_{3} \mathrm{O}_{4}$ (a) and $\mathrm{Co}_{3} \mathrm{O}_{4}$-PANI (b).

shows that the PANI is completely coated on the $\mathrm{Co}_{3} \mathrm{O}_{4}$ and has an impact on the surface of $\mathrm{Co}_{3} \mathrm{O}_{4}$. The analysis above suggests that it is not a simple mix between $\mathrm{Co}_{3} \mathrm{O}_{4}$ and PANI but rather an interaction existing at the interfaces of $\mathrm{Co}_{3} \mathrm{O}_{4}$ nanoparticles and PANI [30].

The XPS spectra of $\mathrm{Co}_{3} \mathrm{O}_{4}$ and $\mathrm{Co}_{3} \mathrm{O}_{4}$-PANI nanoparticles are presented in Figure 4. In Figure 4(a), the spectrum of $\mathrm{Co}_{3} \mathrm{O}_{4}$ samples shows the existence of cobalt, oxygen, and carbon elements at the surface. Two peaks at 780.4 and $795.4 \mathrm{eV}$ correspond to $\mathrm{Co} 2 \mathrm{p}_{3 / 2}$ and $\mathrm{Co} 2 \mathrm{p}_{1 / 2}$ spin-orbit peaks of $\mathrm{Co}_{3} \mathrm{O}_{4}$, which are characteristic of the $\mathrm{Co}_{3} \mathrm{O}_{4}$ phase [31]. The Ols peak centered at $529.8 \mathrm{eV}$ is assigned to the lattice oxygen in the $\mathrm{Co}_{3} \mathrm{O}_{4}$ phase. The relatively small peak $\mathrm{Cls}$ at $284.6 \mathrm{eV}$ is ascribed to elemental carbon which results from the insufficient burning of degreasing cotton. In Figure 4(b), it can be observed that there are chlorine, carbon, nitrogen, oxygen, and cobalt elements presented at the surface of $\mathrm{Co}_{3} \mathrm{O}_{4}$-PANI samples. The $\mathrm{Cl} 2 \mathrm{p}$ peak at $198.4 \mathrm{eV}$ indicates the existence of $\mathrm{Cl}^{-}$which is due to the $\mathrm{HCl}$ solution used in the synthesis of $\mathrm{Co}_{3} \mathrm{O}_{4}$-PANI [32]. The Cls and N1s peaks at 285.5 and $400.2 \mathrm{eV}$ are attributed to the $\mathrm{C}-\mathrm{N}$ and $-\mathrm{NH}$ - from the PANI backbone $[33,34]$. The O1s peak at $532.4 \mathrm{eV}$ is ascribed to hydroxide ions adsorbed on the surface. The characteristic peaks of $\mathrm{Co}_{3} \mathrm{O}_{4}$ at 780.4 and $795.4 \mathrm{eV}$ are very weak. It can be inferred that $\mathrm{Co}_{3} \mathrm{O}_{4}$ core is well covered by PANI and the core-shell $\mathrm{Co}_{3} \mathrm{O}_{4}$-PANI nanocomposite is well synthesized.

To study the microwave absorption properties, reflection loss $\left(R_{L}\right)$ can be used to characterize the microwave absorption capacity, which is affected by morphology, dielectric and magnetic properties, electromagnetic impedance match, and chemical stability of the absorber. $R_{L}$ is calculated according to the transmission line theory [35]:

$$
\begin{aligned}
R_{L}(\mathrm{~dB}) & =20 \log \left|\frac{Z_{\text {in }}-Z_{0}}{Z_{\text {in }}+Z_{0}}\right|, \\
Z_{\text {in }} & =Z_{0} \sqrt{\frac{\mu_{r}}{\varepsilon_{r}}} \tanh \left[j\left(\frac{2 \pi f d}{c}\right) \sqrt{\mu_{r} \varepsilon_{r}}\right],
\end{aligned}
$$

where $Z_{\text {in }}$ is the input impedance of the absorber, $Z_{0}$ is the input impedance of air, $\mu_{r}$ and $\varepsilon_{r}$ are, respectively, the relative complex permeability and permittivity, $f$ is the frequency of the electromagnetic waves, $d$ is the thickness of the absorber, $c$ is the velocity of electromagnetic waves in free space, and $R_{L}(\mathrm{~dB})$ is the reflection loss of the absorber.

Figure 5 shows the relationship between reflection loss and frequency in different thickness for the obtained samples. In Figure 5(a), it can be observed that the $R_{L}$ of $\mathrm{Co}_{3} \mathrm{O}_{4}$ is no more than $-6 \mathrm{~dB}$ when its thickness ranges from 2 to $5.5 \mathrm{~mm}$, and the maximum $R_{L}$ is only $-6.0 \mathrm{~dB}$ at the frequency of $8.3 \mathrm{GHz}$ with a thickness of $5.5 \mathrm{~mm}$. This demonstrates that the $\mathrm{Co}_{3} \mathrm{O}_{4}$ sample exhibits a very weak ability to absorb microwave. In Figure 5(b), it can be found that the microwave absorption properties of $\mathrm{Co}_{3} \mathrm{O}_{4}$ are significantly enhanced by PANI coating. The reflection loss of $\mathrm{Co}_{3} \mathrm{O}_{4}$-PANI is less than $-10 \mathrm{~dB}$ (90\% of microwave absorption) over the frequency range of 3.9-18 GHz when the thickness of sample is between $2 \mathrm{~mm}$ and $5.5 \mathrm{~mm}$. The maximum $R_{L}$ of $\mathrm{Co}_{3} \mathrm{O}_{4}$-PANI is up to $-45.8 \mathrm{~dB}$ at $11.7 \mathrm{GHz}$ and the absorption bandwidths corresponding to the $R_{L}$ values below $-10 \mathrm{~dB}$ are $5.8 \mathrm{GHz}$ (from 9.6 to $14.4 \mathrm{GHz}$ ) when its thickness is $2.5 \mathrm{~mm}$. It is well known that microwave absorption capability relies on the nature shape and size of an absorber [36]. The excellent microwave absorption properties may be due to the special structure and geometrical morphology of the nanocomposite prepared by applying PANI coating on $\mathrm{Co}_{3} \mathrm{O}_{4}$. Furthermore, the thickness of the samples is another critical factor affecting the intensity and the position of the frequency at the maximum reflection losses [37]. It can be seen that the maximum $R_{L}$ values obviously shift to the lower frequency as the thickness increases from 2 to $5.5 \mathrm{~mm}$. They also move to the smaller intensity except the maximum $R_{L}$ value with a thickness of $2.5 \mathrm{~mm}$, which has the maximal intensity of all.

To investigate the microwave absorption mechanism of the $\mathrm{Co}_{3} \mathrm{O}_{4}$-PANI, the relative complex permittivity, permeability, and loss tangent of $\mathrm{Co}_{3} \mathrm{O}_{4}$ and $\mathrm{Co}_{3} \mathrm{O}_{4}$-PANI are 


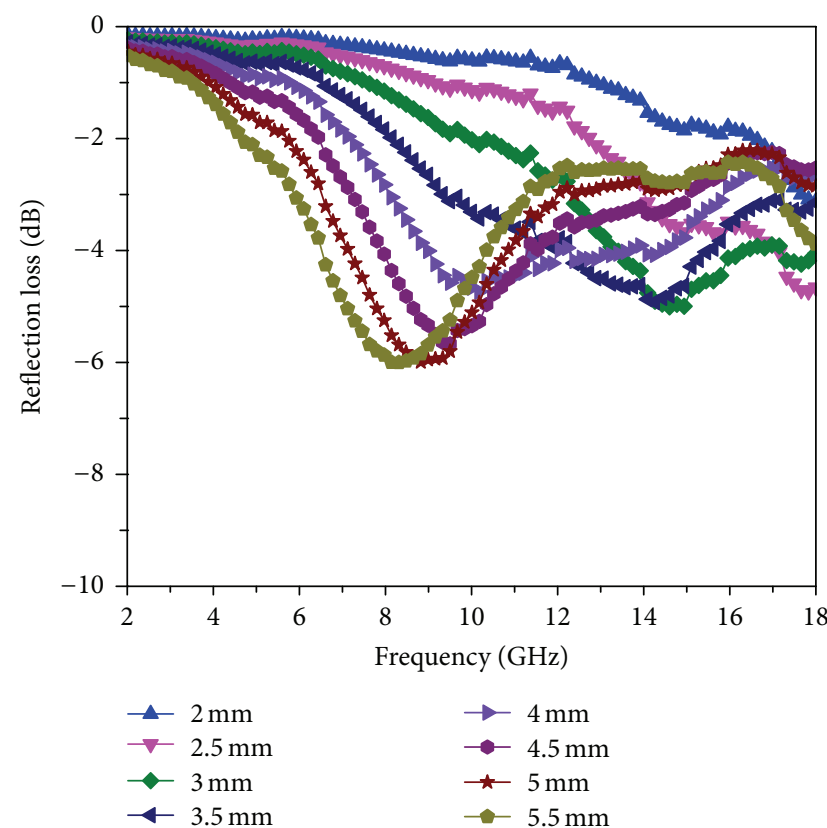

(a)

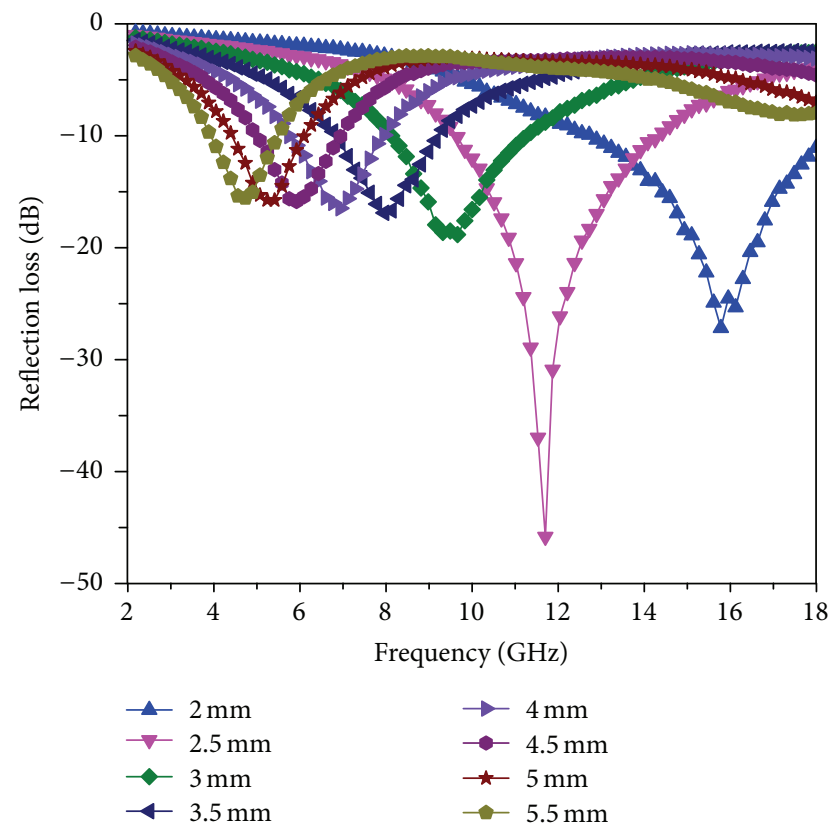

(b)

Figure 5: Microwave reflection loss of $\mathrm{Co}_{3} \mathrm{O}_{4}$ (a) and $\mathrm{Co}_{3} \mathrm{O}_{4}$-PANI (b).

presented in Figure 6 to characterize dielectric loss and magnetic loss properties of absorbers. In Figure 6(a), the real $\left(\varepsilon^{\prime}\right)$ and imaginary $\left(\varepsilon^{\prime \prime}\right)$ parts of relative permittivity of $\mathrm{Co}_{3} \mathrm{O}_{4}$ are around 3.5 and 0.5 , respectively, and both of the two parameters change slowly as the frequency increases. They decrease relatively fast when frequency increases from 2 to $6 \mathrm{GHz}$ and then tend to stabilize with some fluctuations. The fluctuations are related to the resonance behavior caused by the charge polarization of $\mathrm{Co}_{3} \mathrm{O}_{4}$ [38]. Comparing to $\mathrm{Co}_{3} \mathrm{O}_{4}, \mathrm{Co}_{3} \mathrm{O}_{4}$-PANI has much higher and more unstable $\varepsilon^{\prime}$ and $\varepsilon^{\prime \prime}$ values (Figure $6(\mathrm{~b})$ ). The high values are partially due to the strong polarization in PANI generated from polaron/bipolaron and other bound charges [3]. But PANI itself cannot improve the permittivity that much $[30,39]$. The interfacial interaction between the PANI and $\mathrm{Co}_{3} \mathrm{O}_{4}$ core has a great effect on the permittivity, which is attributed to a large number of interfacial polarization charges $[2,40]$. Both the $\varepsilon^{\prime}$ and $\varepsilon^{\prime \prime}$ values decrease rapidly with frequency increasing from 2 to $6 \mathrm{GHz}$. $\varepsilon^{\prime}$ keeps declining until the frequency reaches $18 \mathrm{GHz}$, but $\varepsilon^{\prime \prime}$ stops decreasing at the frequency of $12 \mathrm{GHz}$ and then has a slight rise. The variation of permittivity with frequency can be explained by the interfacial relaxation between $\mathrm{Co}_{3} \mathrm{O}_{4}$ cores and PANI shells, as well as the Debye relaxation of PANI $[3,41]$. As the applied field alters, the charges redistribute alternatively between $\mathrm{Co}_{3} \mathrm{O}_{4}$ cores and PANI shells, and the dipoles in nanocomposites cannot reorient themselves along with the field.

By comparing the relative permeability of Figures 6(c) and 6(d), it is clearly shown that PANI coating almost has no influence on the permeability of $\mathrm{Co}_{3} \mathrm{O}_{4}$-PANI nanocomposite. The real $\left(\mu^{\prime}\right)$ and imaginary $\left(\mu^{\prime \prime}\right)$ parts of relative permittivity of $\mathrm{Co}_{3} \mathrm{O}_{4}$ are slightly above 1.0 and below 0.1 , respectively. Being almost identical to those of $\mathrm{Co}_{3} \mathrm{O}_{4}$, the real and imaginary parts of relative permittivity of $\mathrm{Co}_{3} \mathrm{O}_{4}-$ PANI fluctuate around 1.0 and 0.1, separately. The small difference may be caused by the interfacial interaction where the motion of charges produces an induced magnetic field. The small values indicate that both $\mathrm{Co}_{3} \mathrm{O}_{4}$ and $\mathrm{Co}_{3} \mathrm{O}_{4}$-PANI show a very weak magnetic loss.

Figures 6(e) and 6(f) show the loss tangent of $\mathrm{Co}_{3} \mathrm{O}_{4}$ and $\mathrm{Co}_{3} \mathrm{O}_{4}$-PANI. Apparently, the dielectric loss tangent $\left(\tan \delta_{\varepsilon}=\right.$ $\left.\varepsilon^{\prime \prime} / \varepsilon^{\prime}\right)$ is much larger than the magnetic loss tangent $\left(\tan \delta_{\mu}=\right.$ $\left.\mu^{\prime \prime} / \mu^{\prime}\right)$ for both $\mathrm{Co}_{3} \mathrm{O}_{4}$-PANI and $\mathrm{Co}_{3} \mathrm{O}_{4}$. This indicates that the main absorption mechanism of $\mathrm{Co}_{3} \mathrm{O}_{4}$-PANI and $\mathrm{Co}_{3} \mathrm{O}_{4}$ is dielectric loss. The dielectric loss of $\mathrm{Co}_{3} \mathrm{O}_{4}$-PANI is nearly four times as high as that of $\mathrm{Co}_{3} \mathrm{O}_{4}$. The interfacial interaction between the $\mathrm{Co}_{3} \mathrm{O}_{4}$ cores and PANI shells greatly affects the dielectric loss of $\mathrm{Co}_{3} \mathrm{O}_{4}$-PANI as discussed above. So it can be concluded that the core-shell structure makes a major contribution to the excellent microwave absorption properties of $\mathrm{Co}_{3} \mathrm{O}_{4}$-PANI.

\section{Conclusion}

The $\mathrm{Co}_{3} \mathrm{O}_{4}$ nanoparticle has been synthesized by carbonassisted method using degreasing cotton as a template and coated with PANI using an in situ polymerization method. The XRD, TEM, FTIR, and XPS characterizations show that the $\mathrm{Co}_{3} \mathrm{O}_{4}$ nanoparticle prepared is the spinel structure with average size of around $60 \mathrm{~nm}$ and the $\mathrm{Co}_{3} \mathrm{O}_{4}$-PANI nanocomposite is the core-shell structure with particle size of about $100 \mathrm{~nm}$. Comparing to $\mathrm{Co}_{3} \mathrm{O}_{4}$, the core-shell structured $\mathrm{Co}_{3} \mathrm{O}_{4}$-PANI exhibits greatly enhanced microwave absorption properties. The optimal absorption peak of $\mathrm{Co}_{3} \mathrm{O}_{4}$-PANI 

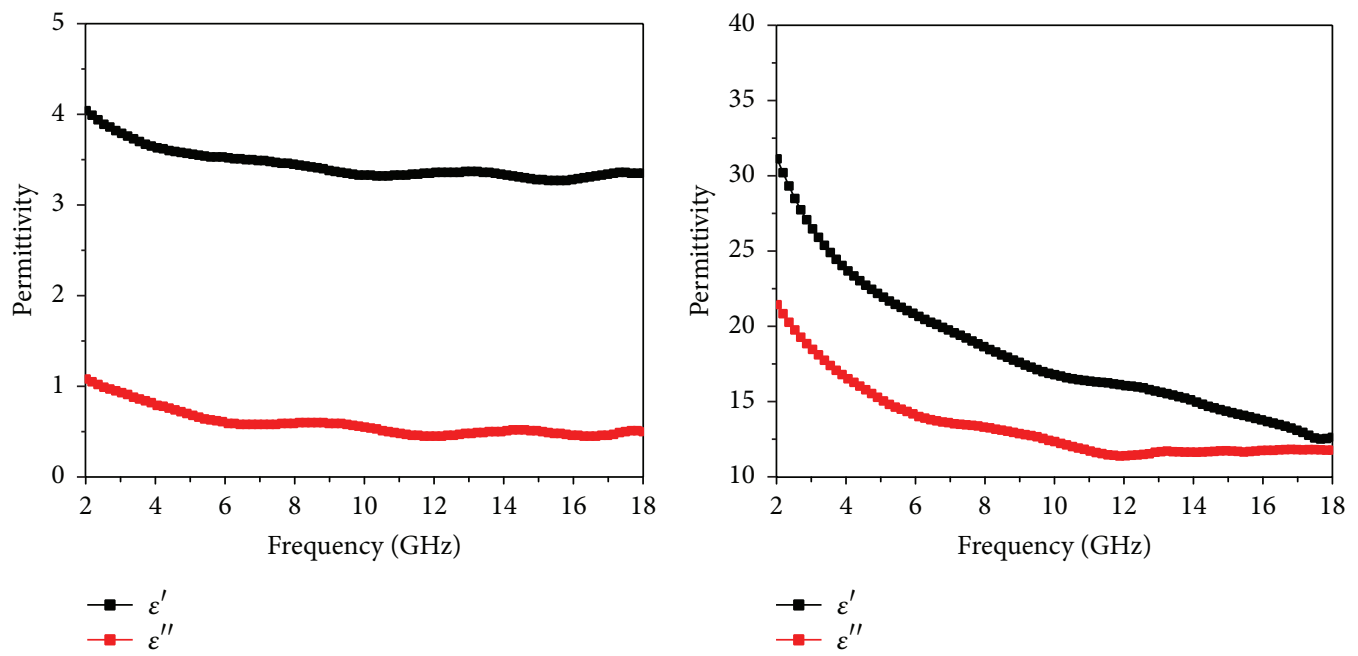

(a)

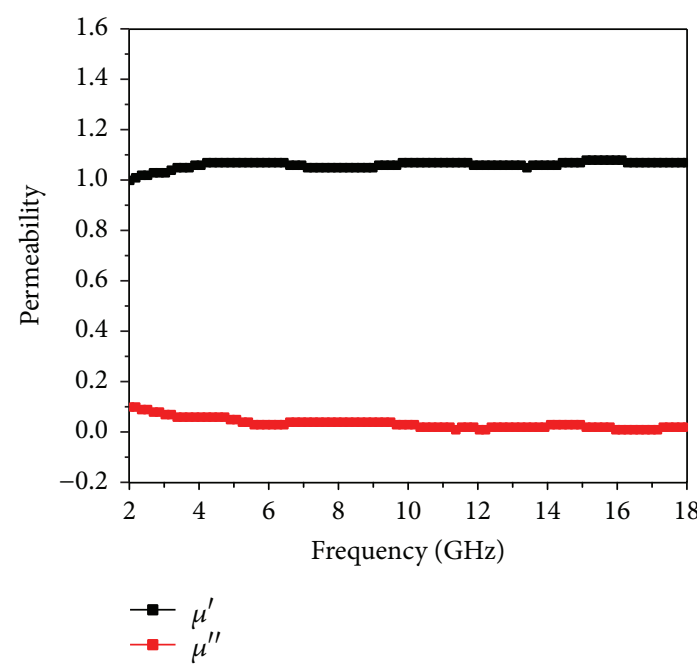

(c)

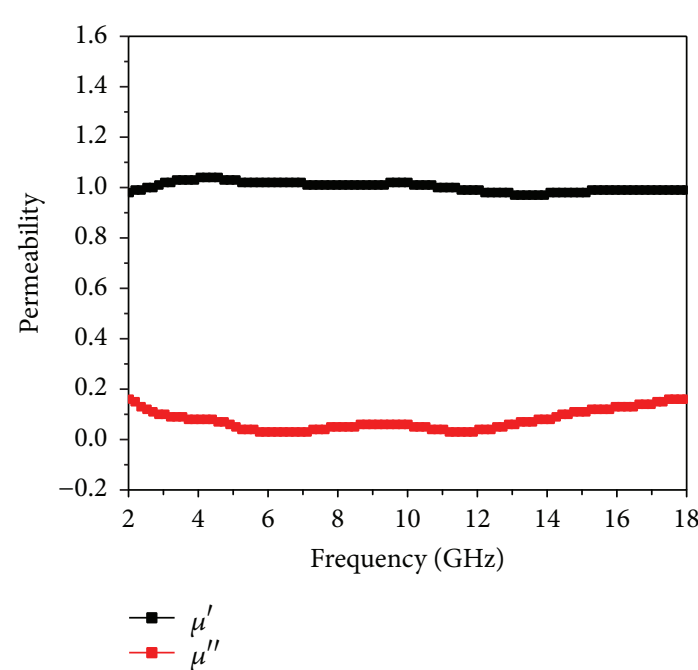

(d)

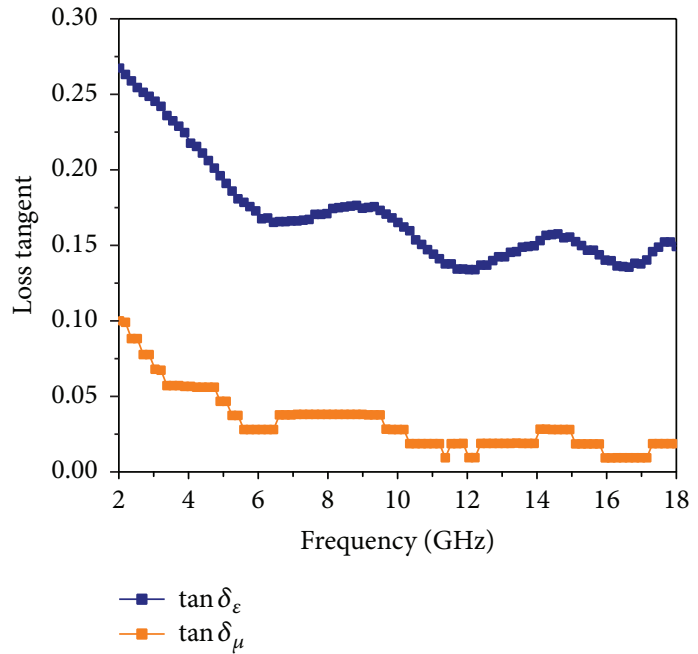

(e)

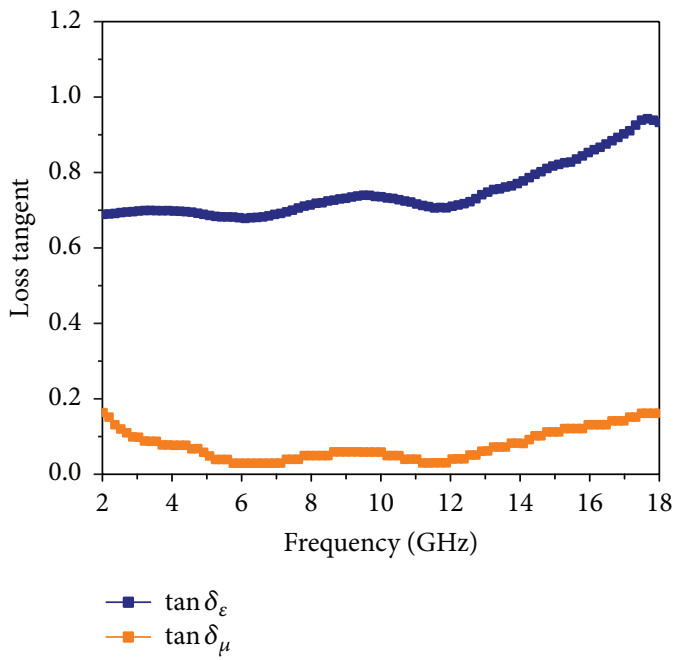

(f)

FIgURE 6: The complex relative permittivity of $\mathrm{Co}_{3} \mathrm{O}_{4}(\mathrm{a})$ and $\mathrm{Co}_{3} \mathrm{O}_{4}$-PANI (b), the complex relative permeability of $\mathrm{Co}_{3} \mathrm{O}_{4}(\mathrm{c})$ and $\mathrm{Co}_{3} \mathrm{O}_{4}-$ PANI (d), and the loss tangent of $\mathrm{Co}_{3} \mathrm{O}_{4}(\mathrm{e})$ and $\mathrm{Co}_{3} \mathrm{O}_{4}$-PANI (f). 
reaches $-45.8 \mathrm{~dB}$ at $11.7 \mathrm{GHz}$ with a thickness of $2.5 \mathrm{~mm}$ and the adsorption bandwidth corresponding to the reflection loss below $-10 \mathrm{~dB}$ is $14.1 \mathrm{GHz}$ (from 3.9 to $18 \mathrm{GHz}$ ) when the thickness is between 2 and $5.5 \mathrm{~mm}$. This is believed to be due to the interfacial interaction of the core-shell structure. The microwave absorption properties of $\mathrm{Co}_{3} \mathrm{O}_{4}$-PANI may be further optimized by varying the ratio of $\mathrm{Co}_{3} \mathrm{O}_{4}$ core and PANI shell during the synthesis process in the future work. The superior microwave absorption properties demonstrate that the core-shell structured $\mathrm{Co}_{3} \mathrm{O}_{4}$-PANI nanocomposite can be a promising nanomaterial for high efficient microwave absorption.

\section{Conflict of Interests}

The authors declare that there is no conflict of interests regarding the publication of this paper.

\section{Acknowledgments}

This work was financially supported by the National Natural Science Foundation of China for Distinguished Young Scholar (Grant no. 51225504) and the National High-Tech Research and Development (863) Program of China (Grant no. 2015AA042600).

\section{References}

[1] J. Qiu and T. Qiu, "Fabrication and microwave absorption properties of magnetite nanoparticle-carbon nanotube-hollow carbon fiber composites," Carbon, vol. 81, no. 1, pp. 20-28, 2015.

[2] F. Wen, H. Hou, J. Xiang et al., "Fabrication of carbon encapsulated $\mathrm{Co}_{3} \mathrm{O}_{4}$ nanoparticles embedded in porous graphitic carbon nanosheets for microwave absorber," Carbon, vol. 89, pp. 372-377, 2015.

[3] K. Singh, A. Ohlan, A. K. Bakhshi, and S. K. Dhawan, "Synthesis of conducting ferromagnetic nanocomposite with improved microwave absorption properties," Materials Chemistry and Physics, vol. 119, no. 1-2, pp. 201-207, 2010.

[4] T. Zhang, B. Zhong, J. Q. Yang, X. X. Huang, and G. Wen, "Boron and nitrogen doped carbon nanotubes $/ \mathrm{Fe}_{3} \mathrm{O}_{4}$ composite architectures with microwave absorption property," Ceramics International, vol. 41, no. 6, pp. 8163-8170, 2015.

[5] T. H. Ting, R. P. Yu, and Y. N. Jau, "Synthesis and microwave absorption characteristics of polyaniline/NiZn ferrite composites in 2-40 GHz," Materials Chemistry and Physics, vol. 126, no. 1-2, pp. 364-368, 2011.

[6] N. Gandhi, K. Singh, A. Ohlan, D. P. Singh, and S. K. Dhawan, "Thermal, dielectric and microwave absorption properties of polyaniline-CoFe $\mathrm{O}_{4}$ nanocomposites," Composites Science and Technology, vol. 71, no. 15, pp. 1754-1760, 2011.

[7] K. Singh, A. Ohlan, V. H. Pham et al., "Nanostructured graphene $/ \mathrm{Fe}_{3} \mathrm{O}_{4}$ incorporated polyaniline as a high performance shield against electromagnetic pollution," Nanoscale, vol. 5, no. 6, pp. 2411-2420, 2013.

[8] M.-S. Cao, J. Yang, W.-L. Song et al., "Ferroferric oxide/multiwalled carbon nanotube vs polyaniline/ferroferric oxide/multiwalled carbon nanotube multiheterostructures for highly effective microwave absorption," ACS Applied Materials \& Interfaces, vol. 4, no. 12, pp. 6949-6956, 2012.
[9] S. C. Petitto and M. A. Langell, "Surface composition and structure of $\mathrm{Co}_{3} \mathrm{O}_{4}(110)$ and the effect of impurity segregation," Journal of Vacuum Science \& Technology A: Vacuum, Surfaces and Films, vol. 22, no. 4, pp. 1690-1696, 2004.

[10] B. Bai, H. Arandiyan, and J. Li, "Comparison of the performance for oxidation of formaldehyde on nano- $\mathrm{Co}_{3} \mathrm{O}_{4}, 2 \mathrm{D}-\mathrm{Co}_{3} \mathrm{O}_{4}$, and 3D- $\mathrm{Co}_{3} \mathrm{O}_{4}$ catalysts," Applied Catalysis B: Environmental, vol. 142-143, pp. 677-683, 2013.

[11] D. Su, X. Xie, P. Munroe, S. Dou, and G. Wang, "Mesoporous hexagonal $\mathrm{Co}_{3} \mathrm{O}_{4}$ for high performance lithium ion batteries," Scientific Reports, vol. 4, article 6519, 8 pages, 2014.

[12] X.-H. Xia, J.-P. Tu, Y.-J. Mai, X.-L. Wang, C.-D. Gu, and X.-B. Zhao, "Self-supported hydrothermal synthesized hollow $\mathrm{Co}_{3} \mathrm{O}_{4}$ nanowire arrays with high supercapacitor capacitance," Journal of Materials Chemistry, vol. 21, no. 25, pp. 9319-9325, 2011.

[13] L. Wang, Y. Ye, Y. Shen et al., "Hierarchical nanocomposites of $\mathrm{Co}_{3} \mathrm{O}_{4}$ /polyaniline nanowire arrays/reduced graphene oxide sheets for amino acid detection," Sensors and Actuators, B: Chemical, vol. 203, pp. 864-872, 2014.

[14] Q. Zhang, L. Gao, X. Chou, J. Diwu, H. Xu, and C. Xue, "Synthesis of octahedral $\mathrm{Co}_{3} \mathrm{O}_{4}$ via carbon-assisted method," Micro \& Nano Letters, vol. 10, no. 2, pp. 85-87, 2015.

[15] L. Gao, J. Diwu, Q. Zhang et al., "A green and facile synthesis of carbon-incorporated $\mathrm{Co}_{3} \mathrm{O}_{4}$ nanoparticles and their photocatalytic activity for hydrogen evolution," Journal of Nanomaterials, vol. 2015, Article ID 618492, 7 pages, 2015.

[16] H. Wu, Q. Wu, and L. Wang, "Design and wide range microwave absorption of porous $\mathrm{Co}-\mathrm{Co}_{3} \mathrm{O}_{4}$ hybrid hollow sphere with magnetic multi-resonance mechanisms," Materials Characterization, vol. 103, pp. 1-10, 2015.

[17] Y. Liu, Z. Zhang, S. Xiao, C. Qiang, L. Tian, and J. Xu, "Preparation and properties of cobalt oxides coated carbon fibers as microwave-absorbing materials," Applied Surface Science, vol. 257, no. 17, pp. 7678-7683, 2011.

[18] P. Liu, Y. Huang, L. Wang, M. Zong, and W. Zhang, "Hydrothermal synthesis of reduced graphene oxide- $\mathrm{Co}_{3} \mathrm{O}_{4}$ composites and the excellent microwave electromagnetic properties," Materials Letters, vol. 107, pp. 166-169, 2013.

[19] P. Liu, Y. Huang, L. Wang, and W. Zhang, "Preparation and excellent microwave absorption property of three component nanocomposites: polyaniline-reduced graphene oxide- $\mathrm{Co}_{3} \mathrm{O}_{4}$ nanoparticles," Synthetic Metals, vol. 177, pp. 89-93, 2013.

[20] P. Liu, Y. Huang, L. Wang, and W. Zhang, "Synthesis and excellent electromagnetic absorption properties of polypyrrolereduced graphene oxide- $\mathrm{Co}_{3} \mathrm{O}_{4}$ nanocomposites," Journal of Alloys and Compounds, vol. 573, pp. 151-156, 2013.

[21] K. R. Reddy, K. P. Lee, and A. I. Gopalan, "Self-assembly approach for the synthesis of electro-magnetic functionalized $\mathrm{Fe}_{3} \mathrm{O}_{4}$ /polyaniline nanocomposites: effect of dopant on the properties," Colloids and Surfaces A: Physicochemical and Engineering Aspects, vol. 320, no. 1-3, pp. 49-56, 2008.

[22] B. Thakur, C. A. Amarnath, S. H. Mangoli, and S. N. Sawant, "Polyaniline nanoparticle based colorimetric sensor for monitoring bacterial growth," Sensors and Actuators, B: Chemical, vol. 207, pp. 262-268, 2014.

[23] C. A. Amarnath, N. Venkatesan, M. Doble, and S. N. Sawant, "Water dispersible Ag@polyaniline-pectin as supercapacitor electrode for physiological environment," Journal of Materials Chemistry B, vol. 2, no. 31, pp. 5012-5019, 2014. 
[24] B. H. Shambharkar and S. S. Umare, "Production and characterization of polyaniline $/ \mathrm{Co}_{3} \mathrm{O}_{4}$ nanocomposite as a cathode of Zn-polyaniline battery," Materials Science and Engineering $B$ : Solid-State Materials for Advanced Technology, vol. 175, no. 2, pp. 120-128, 2010.

[25] Y. Liu, G. Zhu, B. Ge, H. Zhou, A. Yuan, and X. Shen, "Concave $\mathrm{Co}_{3} \mathrm{O}_{4}$ octahedral mesocrystal: polymer-mediated synthesis and sensing properties," CrystEngComm, vol. 14, no. 19, pp. 6264-6270, 2012.

[26] T. He, D. Chen, X. Jiao, Y. Xu, and Y. Gu, "Surfactant-assisted solvothermal synthesis of $\mathrm{Co}_{3} \mathrm{O}_{4}$ hollow spheres with orientedaggregation nanostructures and tunable particle size," Langmuir, vol. 20, no. 19, pp. 8404-8408, 2004.

[27] S. Vijayakumar, A. Kiruthika Ponnalagi, S. Nagamuthu, and G. Muralidharan, "Microwave assisted synthesis of $\mathrm{Co}_{3} \mathrm{O}_{4}$ nanoparticles for high-performance supercapacitors," Electrochimica Acta, vol. 106, pp. 500-505, 2013.

[28] P. Boomi, H. G. Prabu, P. Manisankar, and S. Ravikumar, "Study on antibacterial activity of chemically synthesized PANI-Ag-Au nanocomposite," Applied Surface Science, vol. 300, pp. 66-72, 2014.

[29] W. Zheng, M. Angelopoulos, A. J. Epstein, and A. G. MacDiarmid, "Experimental evidence for hydrogen bonding in polyaniline: mechanism of aggregate formation and dependency on oxidation state," Macromolecules, vol. 30, no. 10, pp. 2953-2955, 1997.

[30] F. Xu, L. Ma, Q. Huo, M. Gan, and J. Tang, "Microwave absorbing properties and structural design of microwave absorbers based on polyaniline and polyaniline/magnetite nanocomposite," Journal of Magnetism and Magnetic Materials, vol. 374, pp. 311-316, 2015.

[31] Z.-S. Wu, W. Ren, L. Wen et al., "Graphene anchored with $\mathrm{Co}_{3} \mathrm{O}_{4}$ nanoparticles as anode of lithium ion batteries with enhanced reversible capacity and cyclic performance," ACS Nano, vol. 4, no. 6, pp. 3187-3194, 2010.

[32] H. Cui, Q. Li, Y. Qian, R. Tang, H. An, and J. Zhai, "Defluoridation of water via electrically controlled anion exchange by polyaniline modified electrode reactor," Water Research, vol. 45, no. 17, pp. 5736-5744, 2011.

[33] S. Golczak, A. Kanciurzewska, M. Fahlman, K. Langer, and J. J. Langer, "Comparative XPS surface study of polyaniline thin films," Solid State Ionics, vol. 179, no. 39, pp. 2234-2239, 2008.

[34] J. Zhang, D. Shu, T. Zhang et al., "Capacitive properties of PANI/ $\mathrm{MnO}_{2}$ synthesized via simultaneous-oxidation route," Journal of Alloys and Compounds, vol. 532, pp. 1-9, 2012.

[35] L. Yan, J. Wang, X. Han, Y. Ren, Q. Liu, and F. Li, "Enhanced microwave absorption of Fe nanoflakes after coating with $\mathrm{SiO}_{2}$ nanoshell," Nanotechnology, vol. 21, no. 9, Article ID 095708, 2010.

[36] P. Liu and Y. Huang, "Decoration of reduced graphene oxide with polyaniline film and their enhanced microwave absorption properties," RSC Advances, vol. 21, no. 5, pp. 1-5, 2014.

[37] T. Chen, F. Deng, J. Zhu et al., "Hexagonal and cubic Ni nanocrystals grown on graphene: phase-controlled synthesis, characterization and their enhanced microwave absorption properties," Journal of Materials Chemistry, vol. 22, no. 30, pp. 1519015197, 2012.

[38] H. Wu, L. Wang, Y. Wang, and S. Guo, "Microwave absorption properties of $\mathrm{CeO}_{2}$ and $\mathrm{Zn}$-modified $\mathrm{CeO}_{2}$ microstructures," Applied Surface Science, vol. 258, no. 24, pp. 10047-10052, 2012.
[39] M. Oyharçabal, T. Olinga, M.-P. Foulc, S. Lacomme, E. Gontier, and V. Vigneras, "Influence of the morphology of polyaniline on the microwave absorption properties of epoxy polyaniline composites," Composites Science and Technology, vol. 74, pp. 107-112, 2013.

[40] H. Qin, Q. Liao, G. Zhang, Y. Huang, and Y. Zhang, "Microwave absorption properties of carbon black and tetrapod-like $\mathrm{ZnO}$ whiskers composites," Applied Surface Science, vol. 286, pp. 711, 2013.

[41] S. S. S. Afghahi and A. Shokuhfar, "Two step synthesis, electromagnetic and microwave absorbing properties of FeCo@C core-shell nanostructure," Journal of Magnetism and Magnetic Materials, vol. 370, pp. 37-44, 2014. 

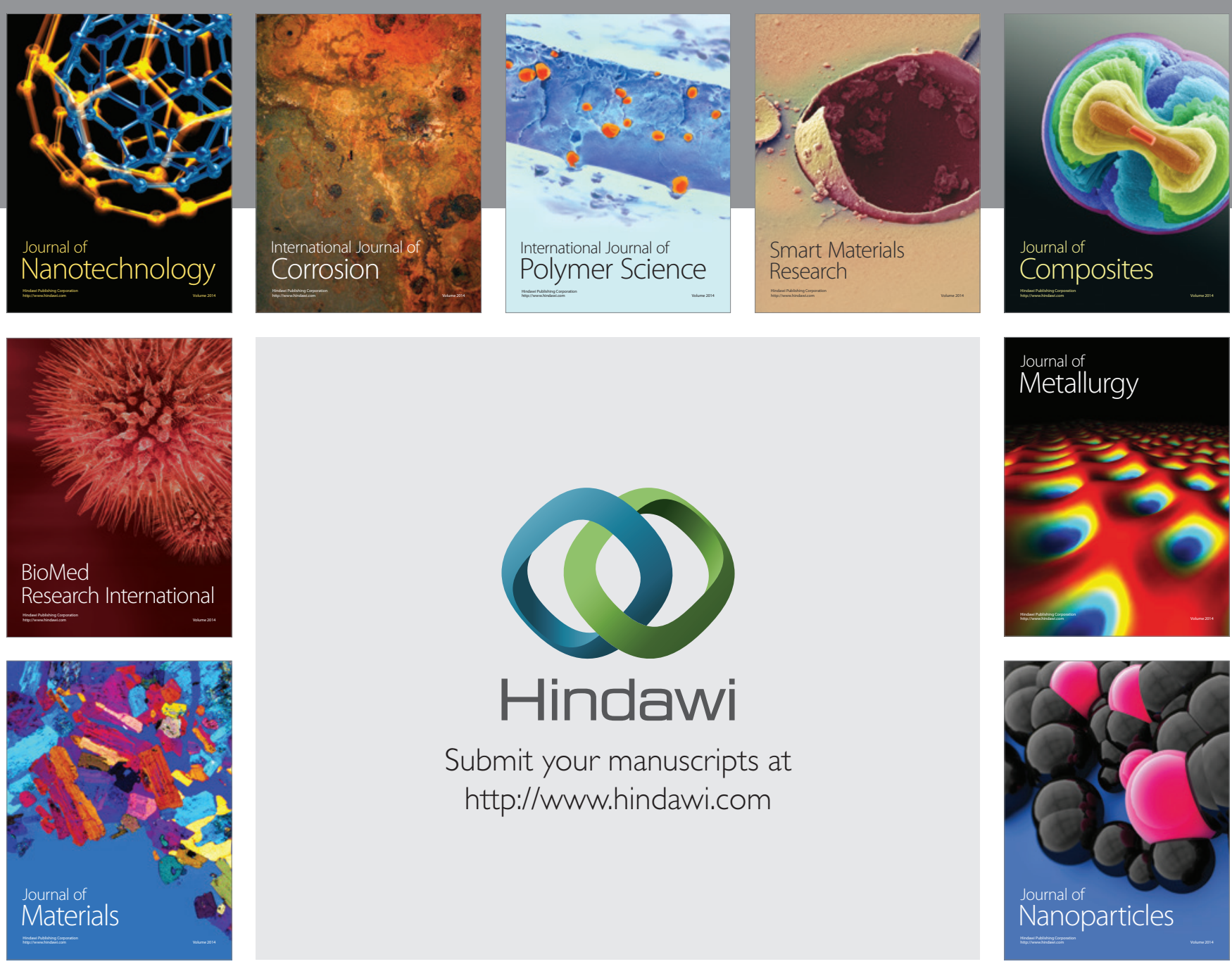

Submit your manuscripts at http://www.hindawi.com
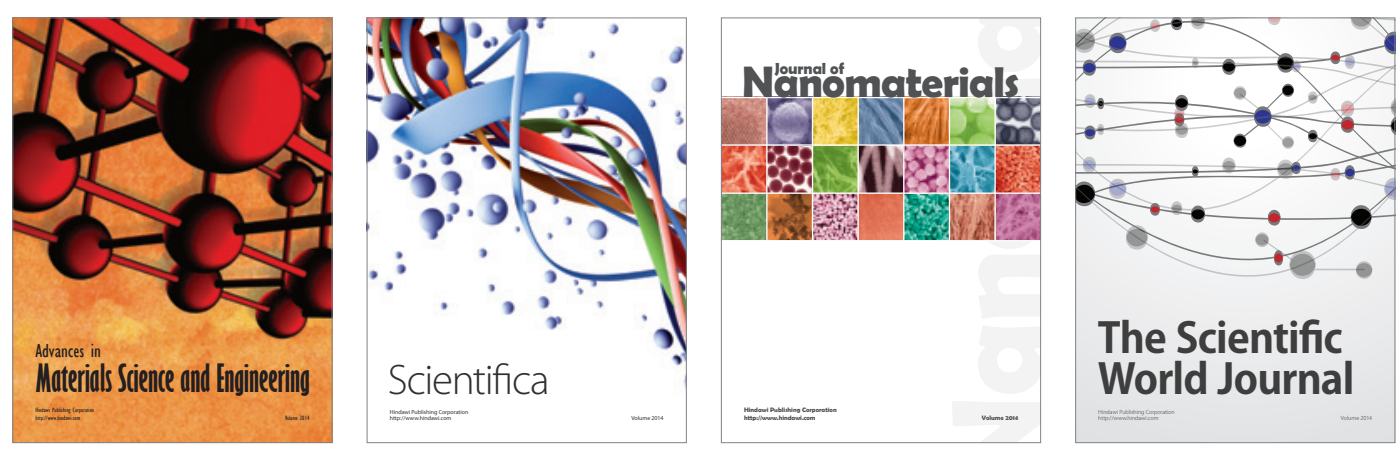

\section{The Scientific World Journal}
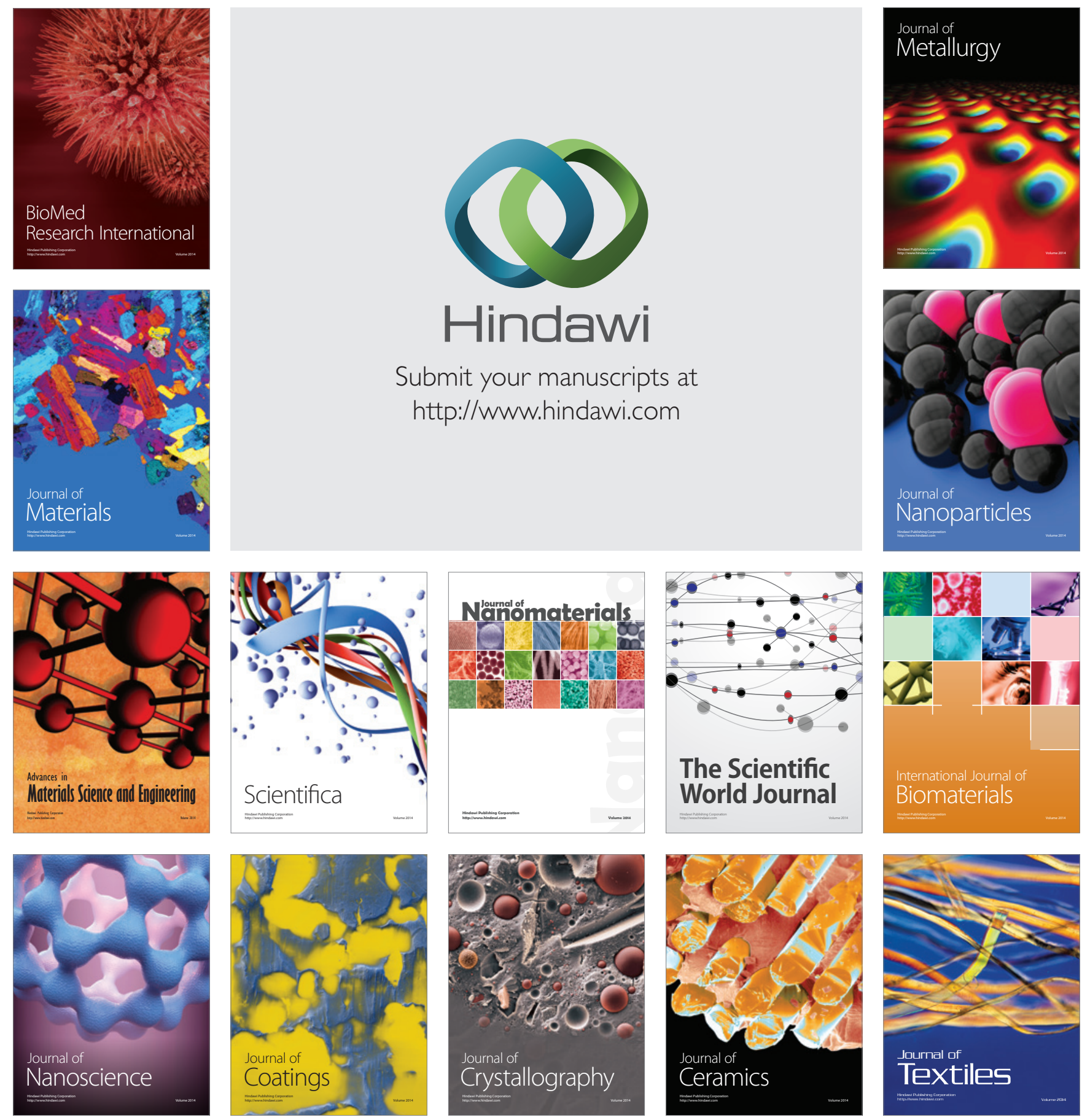